\title{
Linchamientos en Chile. Una aproximación a su comprensión a partir de la descripción de las relaciones entre derecho y violencia que emergen de relatos de prensa del año 2012
}

Loreto Quiroz Rojas*

\begin{abstract}
Resumen
El presente texto da cuenta de un fenómeno incipiente en Chile, los linchamientos, entendidos estos como "una acción colectiva, punitiva, que puede ser anónima, espontánea u organizada, con diferentes niveles de ritualización, que persigue la violencia física sobre individuos que presumiblemente han infringido una norma, sea esta formal o virtual (es decir, instituida por la colectividad), y que se encuentran en considerable inferioridad numérica" (Fuentes, 2005: 8). Basado en información de prensa, este trabajo explora en el sentido de estas acciones en relación al derecho. La pertinencia de este enfoque deviene del objeto de los linchamientos, esto es el castigo por la comisión de hechos valorados como reprochables, función que los Estados ejercen por medio de su derecho.
\end{abstract}

Palabras clave: Linchamientos - violencia - derecho.

\begin{abstract}
This paper analyzes a new phenomenon in Chile, lynchings. This article defines lynchings as "collective punitive actions which may be anonymous, spontaneous or organized, with different levels of ritualization, chasing physical violence on individuals who presumably have broken a formal or virtual rule (rule elaborated by the community), and are considerably outnumbered" (Fuentes, 2005: 8). This paper analyzes the information about lynchings in newspapers, and explores the meaning of these actions for the legal system. The relevance of this analysis is the objective of the lynchings which is the punishment for breaking a rule, objective that each State establishes as the objective of the legal system.
\end{abstract}

Keywords: Lynchings - violence - legal system.

* Abogada y Magíster en Ciencias Sociales, Universidad de Chile. Coordinadora del Programa de Antropología Jurídica de la Facultad de Derecho de la Universidad de Chile. 


\section{INTRODUCCIÓN}

El presente texto da cuenta de un fenómeno incipiente en Chile, los linchamientos, entendidos estos como:

"... una acción colectiva, punitiva, que puede ser anónima, espontánea u organizada, con diferentes niveles de ritualización, que persigue la violencia física sobre individuos que presumiblemente han infringido una norma, sea esta formal o virtual (es decir, instituida por la colectividad), y que se encuentran en considerable inferioridad numérica" (Fuentes, 2005: 8).

De acuerdo con esta definición, es la intencionalidad del despliegue de violencia sobre el cuerpo de el o los individuos que se sindican como infractores uno de los elementos que permite identificar una acción como linchamiento y no la efectividad del despliegue de dicha violencia.

La ocurrencia de estas acciones ha llamado la atención de los medios de comunicación. Los archivos periodísticos mencionan datos acerca del hecho que motiva la violencia, cómo supo el grupo involucrado de la ocurrencia de este hecho, en qué tipo de espacios se ejerce la violencia -públicos (calles, plazas, fuera de comisarías) o privados (vivienda del supuesto victimario)-, qué sucede dentro del grupo involucrado durante el episodio de violencia, cuál es la actitud del grupo frente a la llegada de la policía y en qué consiste la intervención de esta. Sobre la base de estos datos la presente investigación explora en el sentido de estas acciones.

\section{APROXIMACIONES DESDE LAS CIENCIAS SOCIALES EN LATINOAMÉRICA}

Estas acciones se han asociado en el contexto latinoamericano al mundo rural y a la persistencia del derecho indígena como mecanismo de los sectores populares para reapropiarse de la potestad jurídica del Estado (González et al., 2011). Los linchamientos son explicados entonces como manifestaciones de procesos de modernización defectuosos.

Una interpretación diferente nos da Antonio Fuentes (2005), al explicarlos como reacciones frente a un Estado que se percibe como ausente o ineficaz. Estas acciones se leen entonces como actos que se inscriben en la racionalidad propia de la modernidad. Esta manera de interpretar los linchamientos permite comprender la ocurrencia de estas acciones en espacios urbanos, con actores cuyo único acto común es justamente participar de un linchamiento (Rodríguez y Mora, 2005)

Una de las características principales de estas acciones en Argentina sería su objetivo de interpelación hacia el Estado con el objeto de evitar que el crimen quede sin castigo; el accionar desplegado mostraría objetivos prácticos y límites (González et al., 2011). Para el caso mexicano se señala que se lincha al mismo tiempo al delincuente y al símbolo de la autoridad; la acción es también rechazo a la corrupción e impunidad (Rodríguez y Mora, 2005).

Diversos autores coinciden a la hora de reflexionar respecto del fenómeno en que este se da en espacios empobrecidos en los que la población pone en entredicho la autoridad 
pública, ya sea por su ausencia o por la desconfianza que genera (Fuentes, 2006; Rodríguez y Mora, 2008; Carrión, 2008). Así, por ejemplo, se identifican los linchamientos como actos de pobres contra pobres, unos y otros compartiendo la misma falta de justicia institucional (Fuentes, 2006). Los linchamientos constituirían una forma de señalar que los límites han sido rotos y que es necesario reestablecerlos; son expresión de la ruptura de los códigos morales que vinculan a sociedad y autoridad, lo que Durkheim denomina anomia (Rodríguez y Mora, 2005).

Coincidiendo en muchos aspectos con las concepciones anteriores, existen autores que relevan la centralidad de la noción de justicia en la ocurrencia de estos hechos, como base fundante que motiva estos actos (Sinhoreto, 1988; González et al., 2008).

En el caso chileno se constata la falta de desarrollo de una reflexión sobre los linchamientos desde las ciencias sociales. A su vez, la información generada por instituciones como las policías -Carabineros e Investigaciones-, el Ministerio Público o la Defensoría Penal Pública no permite determinar cuándo, cuánto, dónde y cómo se desarrollan los fenómenos que se pretenden estudiar, en tanto estos pueden formar parte de distintas categorías de delitos y estar agrupados con hechos de naturaleza muy diversa.

\section{LA PERTINENCIA DE LA REFLEXIÓN SOBRE LOS LINCHAMIENTOS A PARTIR DEL DERECHO}

La violencia es un elemento central en la teoría del derecho, tanto en sus vertientes liberales como marxistas. En la tradición liberal el derecho aparece como un límite a la violencia por medio de la monopolización que el Estado tendría sobre esta. En términos de las teorías contractualistas, el Estado y su derecho, al monopolizar la violencia, aparecen como garantes de la paz entre los particulares (Rodríguez, 2011). Por el contrario, desde la teoría marxista se indica que el derecho legitima la violencia y se convierte así en su cómplice (Rodríguez, 2011). En esta línea se afirma que todo derecho está fundado en la violencia, tanto la revolucionaria que lo instaura como la estatal que lo mantiene (Benjamin, 1998).

Si bien es cierto que tanto la teoría marxista como la teoría liberal hacen referencia a la violencia a la hora de definir lo que se entiende por derecho, en ambos casos excluyen una reflexión relativa a la violencia misma (Rodríguez, 2011). Esto se traduce en que todo hecho que implique el despliegue de violencia no legitimada institucionalmente por el derecho del Estado tiende a ser comprendido como un espacio-tiempo en que el derecho se ausenta. Se desconoce así que ambas categorías se construyen socialmente (Pérez, 1996). En particular, el derecho es una función de la estructura social, una expresión de las relaciones sociales de fuerza, del grado de dependencia y vinculación de los grupos sociales (Elias, 2009).

Los cambios del derecho deben ser comprendidos entonces no como la progresión lineal y acumulativa de la razón, sino que deben ser inscritos en el contexto mayor en el que la esfera jurídica se inserta. Desde esta perspectiva resulta clave el concepto de paradigma desarrollado por Thomas Kuhn, en tanto es "toda la constelación de creencias, valores, técnicas, etc., compartidos por los miembros de una comunidad dada" (2004: 269), la que en definitiva 
permite explicar el derecho en un espacio-tiempo determinado. Este acercamiento permite visibilizar el derecho más allá de las normas positivas que emanan del Estado y develar las relaciones de autonomía, cooptación, desconocimiento, reemplazo, reclamos u otras que pudieran existir entre la violencia propia de los linchamientos y el derecho.

Al respecto resulta pertinente señalar que, siguiendo a Boaventura de Sousa Santos (2009), al referirnos al derecho no solo hacemos alusión a las normas mediante las cuales se procesan formalmente los conflictos que surgen a partir de las conductas reprochables, sino que también entendemos que el derecho comprende las instituciones que ponen en acción a esas normas, los operadores de dichas instituciones y sus formas de operación.

Es necesario destacar que nos referiremos al derecho como un todo y no solo a alguna de sus ramas, porque los fenómenos que permiten comprenderlo en tanto constructo social nos remiten al derecho en su conjunto y a elaboraciones tan centrales en este como el Estado y la igualdad jurídica. Es por ello que, a pesar del coincidente carácter represivo de los linchamientos y el derecho penal, para aproximarnos a una descripción comprensiva de estas acciones el reflexionar exclusivamente desde las categorías propias de esta rama del derecho implicaría perder parte fundamental de la explicación.

\section{MÉTODO}

Aun cuando fuera de Chile se han realizado diversas investigaciones acerca de los linchamientos, estas reflexiones abordan el fenómeno desde perspectivas diferentes a la propuesta por el presente trabajo. En razón de ello la investigación es de tipo exploratorio-descriptivo.

En tanto derecho y violencia son observados como construcciones sociales en el sentido en el que Berger y Luckmann (1968) utilizan la expresión, la metodología cualitativa resulta pertinente, por cuanto esta se orienta a la búsqueda del significado de las acciones.

Para poder producir el tipo de información requerida por las necesidades generadas por esta aproximación al objeto, se debe lograr un relato lo más minucioso posible acerca de los hechos involucrados en los linchamientos. Este tipo de información permitirá una descripción de estos fenómenos desde la que se infiera el sentido que estas acciones tienen, "qué situaciones reales y problemas prácticos de la vida de la gente resuelven" (Pérez, 1996: 62).

En tanto es improbable poder observar directamente estas acciones, se debe recurrir a los relatos posteriores a estos fenómenos que sea posible recabar. De entre la diversidad de instrumentos a los que se podría recurrir, se optó por trabajar con archivos de prensa disponibles en medios de prensa escritos que circulan diariamente en sus versiones electrónicas, ya que pesquisar estos antecedentes resultaba más accesible ${ }^{1}$. Por lo demás la utilización

1 En relación con este punto es preciso destacar que, si bien es cierto los diversos hechos que en conjunto permiten hablar de la acción de linchamiento pueden corresponder a distintos delitos, cuasidelitos o faltas tipificados por el derecho penal (homicidio, lesiones, riña, daños, robo, etc.), el linchamiento mismo no constituye una figura penal propiamente tal y por tanto identificar los partes policiales o expedientes judiciales que puedan 
de medios de comunicación de masas resulta especialmente pertinente al objetivo de la presente investigación, en tanto estos medios reflejan ordenamientos institucionales de la sociedad (Krippendorff, 1990).

La muestra se restringió a tres medios de prensa: los periódicos La Nación, El Mercurio y La Cuarta. La elección de los medios de prensa referidos se justifica en que estos representan líneas editoriales y públicos objetivos muy disímiles, cuestión que hace posible que cada uno de ellos aporte información particular respecto de los linchamientos.

Los periódicos escogidos cubren acontecimientos ocurridos a lo largo del territorio chileno, por lo que la revisión de estos permite evitar la restricción espacial de la muestra, cuestión relevante si se considera que el presente estudio es de tipo exploratorio-descriptivo.

El archivo de noticias respecto del que se trabajó estuvo delimitado por un criterio cronológico, el año 2012, año que corresponde al periodo más próximo al tiempo en el que se comenzó a trabajar en el análisis de la información, lo que permitió contar con información lo más reciente posible.

Las unidades de muestreo están constituidas por cada episodio de linchamiento, sea que existan uno o más archivos de prensa que den cuenta de cada uno de ellos. La identificación de cada episodio de linchamiento se realizó a base del lugar y fecha de su ocurrencia o publicación. Se entiende que se trata de un mismo lugar -aun cuando la información contenida en las fuentes den cuenta de distintos niveles espaciales (comuna, barrio, población, calle, etc.) - en la medida en que la información que corresponda a los niveles más limitados pueda inscribirse dentro de las zonas comprendidas en los datos que aluden a territorios más amplios. Como resultado se encontraron 29 notas de prensa, de las que se extrajeron 17 unidades de muestreo.

La fuente de los fragmentos de archivos de prensa que se citan en el presente texto se identifica entre paréntesis al final de cada cita, mediante el número asignado a la unidad de muestreo en la primera columna del cuadro que identifica estas unidades, el que se incluye como anexo al presente texto. En el caso de las unidades de muestreo que tienen como fuente más de un archivo de prensa, al referido número se acompaña con una letra, la que identifica el archivo específico que constituye la fuente de la cita y que corresponde a la letra entre paréntesis que aparece en la quinta columna de dicho cuadro.

La técnica utilizada corresponde al análisis de contenido. Esta resulta pertinente en tanto se procura comprender los linchamientos como acciones portadoras de información acerca de la relación entre derecho y violencia, fenómeno que se sitúa en un nivel abstracto respecto del cual los linchamientos podrían representar una especie de huella (López, 2002).

contener información sobre estas acciones implicaría un universo inicial de documentos inabarcable, aun cuando la búsqueda se acotara a un territorio determinado. 


\section{ANÁLISIS DE RESULTADOS}

\subsection{Indicios de normalización de los linchamientos}

El derecho, antes que un sistema de enunciados normativos perentorios, es un conjunto de prácticas, las que se constituyen como tales en tanto resultan funcionales a las estructuras sociales a las que responden.

Siguiendo la propuesta de Berger y Luckmann (1968), los acuerdos sociales de los que emerge el derecho se hacen manifiestos en prácticas, por tal razón la ocurrencia de acciones que disienten de este podría revelar la existencia de consensos sociales a los que no está totalmente ajustado, e incluso la emergencia de un tipo de derecho distinto.

De acuerdo con estas reflexiones, lo primero que convendría examinar es si efectivamente los linchamientos se constituyen como una práctica que presenta patrones comunes, cuestión que daría indicios de una incipiente elaboración normativa en tanto implica que estas acciones, por responder a necesidades generadas por las estructuras sociales, podrían gozar de cierta legitimidad, a la vez que, en función de esa misma legitimidad, podrían incidir en el dinamismo de esas estructuras. "Si en el interior de los grupos se admiten ciertas acciones, es porque estas operan como conjunto de reglas y recetas que se han manifestado como buenas hasta el presente y de las que se espera que sigan funcionando" (Pérez, 1996: 88).

\subsubsection{Carácter público/privado de los linchamientos}

De los archivos examinados se observa que en la mayoría de los casos los linchamientos se desarrollaron en espacios públicos. En algunas ocasiones la información referida a este punto aparece de manera explícita y en otras ocasiones se puede inferir del relato.

En los casos en los que no es posible inferir que la acción de linchamiento ocurrió en un espacio público, tampoco se puede concluir que se desarrolló en un espacio privado. Sin embargo, de los relatos contenidos en los artículos periodísticos referidos a estos casos se advierte que estas acciones se realizan abiertamente.

Resulta entonces que todos los casos son coincidentes en cuanto al carácter público de estas acciones, cuestión que constituiría un indicio de su legitimación en tanto revela que los comportamientos asociados a los linchamientos son aprobados o al menos no abiertamente reprobados por quienes transitan por los espacios en los que se dan en el momento en que estas acciones se desarrollan.

Sin embargo, la información disponible en los archivos de prensa no contiene evidencia que permita afirmar la legitimación de estas acciones más allá del momento y el espacio en el que se sitúan, por lo que solo se aprecia a partir del público el despliegue de los linchamientos, un indicio de normalización emergente y situada.

En la muestra existen dos casos que pueden ser especialmente reveladores respecto de la posibilidad de legitimación de los linchamientos, por cuanto la violencia implicada en 
estos casos se despliega no solo en espacios que tienen el carácter de públicos, sino que se trata de lugares que están asociados justamente a instituciones relacionadas con la operación del derecho. "A la salida del tribunal decenas de familiares y vecinos... lo esperaban para hacer justicia con sus propias manos" $(8, b)$; "Cuando el sujeto fue llevado a la comisaría para realizar el control de detención, los tocopillanos comenzaron a atacar el recinto" $(6, b)$.

\subsubsection{Desarrollo de los linchamientos}

En todos los casos de la muestra los linchamientos se presentan como acciones colectivas gatilladas como respuesta a una ofensa previa. La ofensa aparece como un mal que supera la esfera del individuo específicamente afectado, en tanto la acción de linchamiento supera a los individuos personalmente ofendidos y sus familiares directos.

Examinadas las formas en las que se toma conocimiento de los hechos, no se advierten canales formales de comunicación. En los casos en que el relato de prensa revela la presencia de instituciones del derecho del Estado, estas no aparecen vinculadas a la forma en la que se toma conocimiento del hecho que desencadena el linchamiento, sino que figuran como parte del escenario en el que se desarrolla la acción: "acusado se encontraba en el interior del recinto policial, hasta donde llegó la turba enyegüecida" (6, a), o como un antecedente de esta, "la progenitora lo denunció a la fiscalía... El hombre quedó sin ninguna medida cautelar y volvió bien suelto de cuerpo a su barrio" (18).

En el desarrollo de la acción misma se advierten importantes similitudes con independencia del delito de que se trate, desde robos menores a violaciones con homicidios. Las distintas ofensas se vuelven equivalentes desde el punto de vista de la reacción. La similitud en el desarrollo de la acción permite afirmar que lo que se juega en los linchamientos, sin perjuicio de la idea de venganza, es una especie de defensa autárquica frente a los actos que transgreden el orden social. Estas formas autárquicas de resolución de conflictos resultan funcionales en contextos en los que el poder central es débil para regular las disputas de las personas y así pacificar los espacios sociales en los que estas interactúan; es entonces cuando la violencia social suele proliferar (Tilly, 2007). Sin embargo, pareciera que dicha autarquía es relativa porque el desarrollo de estas acciones siempre desemboca en la llegada de los operadores del sistema jurídico, la policía, a lo que en algunos casos se suma la apelación a su intervención por parte de quienes participan del linchamiento.

\subsection{Los linchamientos, una forma de expresión de la solidaridad mecánica}

La cohesión social del grupo que las formas de interacción mediadas por la violencia reforzarían estarían marcadas por el mecanismo de integración identificado como solidaridad mecánica, el que se basa en las semejanzas y que es propio de sociedades en las que predominan prácticas asociadas a una escasa diferenciación funcional (Durkheim, 1995).

En el marco de sociedades de estas características los sujetos inscriben el sentido de sus acciones en un espectro limitado en cuanto a los otros sujetos a los que remiten su actuar, 
las interacciones son breves en el tiempo y acotadas en cuanto al espacio, la realidad de los individuos está dada solo por su entorno inmediato en tanto dependen escasamente de otros sujetos y de otros territorios para su subsistencia (Elias, 2009).

\subsubsection{Indiferenciación al interior de la muchedumbre que participa del linchamiento}

De acuerdo con la mayoría de los relatos de prensa examinados, la muchedumbre que participa del linchamiento es descrita como una masa indiferenciada. En otras ocasiones se identifican a los sujetos que componen esa masa por medio de un atributo común, así por ejemplo compañeros de trabajo, padres, apoderados, transeúntes y familiares.

En un pequeño grupo de casos encontramos diferenciaciones respecto de quienes participan del linchamiento, sin que a su vez se haga referencia a la existencia de algún tipo de especialización de funciones en el desarrollo de la acción, así por ejemplo se relata: "El que salió [pareja de la víctima de robo] junto a otros sujetos con palos y piedras"( 3 , a); "Peatones y vecinos del sector... se acercaron a los sujetos y sin mediar diálogo los golpearon" (4); "El ladrón fue rodeado por la loína [la víctima] y su hijo y también por quienes transitaban..." (5).

La forma de integración social de la que estarían dando cuenta los linchamientos correspondería entonces a lo que Durkheim (1995) identificó como solidaridad mecánica. Lo anterior se podría objetar en razón de la limitada información que ofrecen las notas de prensa, no obstante el que ninguno de los casos presente una diferencia en este aspecto resulta revelador.

Es preciso destacar que el mismo Durkheim (1995) sostiene que la administración del derecho represivo, por responder a sentimientos colectivos, tiende históricamente a permanecer difusa. En razón de ello la ocurrencia de linchamientos podría no ser una cuestión problemática para el derecho moderno.

Sin embargo, de acuerdo con el mismo autor para el caso de la sociedad contemporánea, en una sociedad altamente diferenciada las formas predominantes de integración corresponden a la solidaridad orgánica, la que se manifiesta mediante mecanismos de integración en razón de la diferencia (Durkheim, 1995). La regularidad y los indicios de legitimación de acciones que no calzan con dicha forma de integración permiten al menos dudar de la completa funcionalidad del derecho en relación con el estado presente de la sociedad.

\subsubsection{Extensión temporal y espacial de los linchamientos}

En la mayoría de los casos examinados, el despliegue de los actos violentos que constituyen los linchamientos, esto es, la violencia que se intenta desplegar sobre el cuerpo del supuesto ofensor, terminan cuando llega la policía.

En un grupo menor de casos, del contenido de los archivos de prensa se desprende que los actos que implican proferir daño físico al cuerpo del sujeto linchado cesaron antes de la llegada de la policía, pero quienes participan del linchamiento retienen al sujeto hasta 
la Ilegada de esta. "Carabineros se hizo presente en el sitio, Ilevándolo detenido tras recibir una golpiza de los pobladores" (5); "Fue rodeado, dieron aviso a Carabineros y los efectivos policiales vieron que el sujeto lucía diversas magulladuras" (7). De acuerdo con lo anterior se aprecia que en estos casos el episodio se cierra también con la llegada de la policía, por cuanto la retención del sujeto igualmente implica el despliegue de violencia sobre su cuerpo y la acción del colectivo centrada en el ofensor termina cuando la policía se hace cargo de este.

En un par de casos, si bien la actuación de los agentes del Estado marca el fin del episodio, la presencia de operadores del sistema jurídico es una constante durante el desarrollo del linchamiento, o al menos es posible inferir su presencia. "Quien ingresó a las dependencias del tribunal escoltado por funcionarios de Gendarmería" (8, a); "Manifestantes [marcha del 21 de mayo] habrían tratado de linchar a dos sujetos al descubrir que estos eran en realidad detectives de la Policía de Investigaciones"(12).

Existen otros casos en los que, aun cuando la actuación de la policía clausura el linchamiento en tanto acción centrada en el ofensor, no pone fin al despliegue de la violencia. "Cerca de las 7 de la mañana Carabineros trataba de disuadir y dispersar a la muchedumbre que seguía destruyendo el auto, encendiendo barricadas y causando destrozos" (1, a); "Al final lo que aparecía como una protesta para pedir que se hiciera justicia, fue aprovechada por los vándalos para hacer de las suyas y provocar daños en la propiedad pública y privada" $(6$, b). En estos casos la violencia se expande y adquiere una especie de vida propia que encuentra en el linchamiento que la desencadena originalmente solo un punto de arranque.

El único caso en que la presencia de la policía no clausura el linchamiento es el que tiene como resultado la muerte del linchado. "El cuerpo fue hallado por vecinos en la misma esquina donde se habría sufrido el supuesto asalto... La Brigada de Homicidios aún busca a los culpables" $(3$, a). De acuerdo con el texto, la policía llega al lugar una vez que la acción ha terminado.

Se observa entonces que los brotes de violencia asociados a los linchamientos en la mayoría de los casos son acotados al hecho que los desencadena, empiezan a propósito de la toma de conocimiento de un hecho determinado y terminan cuando un operador del derecho, generalmente la policía, interviene. En los casos en los que la violencia prosigue pese al accionar de los operadores del derecho, esta pareciera tomar un cariz distinto: ya no tiene como objetivo proferir daño al cuerpo de un sujeto específico. Es viable afirmar que en estos casos si bien es cierto la intervención de los operadores del sistema jurídico no pone fin al despliegue de violencia de inmediato, sí pone fin al linchamiento. La violencia, en tanto se desprende del acto que la origina, se transforma en algo distinto de un mecanismo de autodefensa frente a una agresión. Sin embargo, igualmente dichas violencias se relacionan: la violencia implicada en los linchamientos aparece como parte de una cadena en la que distintos tipos de violencia se conectan y responden unas a otras (Auyero, 2013).

No existen datos en los relatos que permitan dar cuenta de procesos de articulación social que antecedan a los linchamientos, ni de residuos de organización que surjan a partir de estos episodios. 
En cuanto al espacio en el que se dan estas acciones, se aprecia que la mayoría se circunscribe al lugar en el que se produce el hecho que origina el linchamiento y sus alrededores, sin mayores desplazamientos hacia otros territorios, circunstancia que permitiría sospechar que el sentido de la acción se inscribe en el espacio local, lo que a su vez pondría de manifiesto bajos grados de interdependencia respecto de espacios de mayor extensión en relación con estas acciones. Esto, unido a la brevedad temporal del desarrollo de estas acciones, revelaría que en el transcurso de estas existiría escasa relación entre los individuos que participan de los linchamientos, entre estos y otros sujetos que no participan de estas acciones y entre los territorios en los que estas acciones se producen y espacios territoriales más extendidos.

Sin embargo, existen circunstancias que permiten poner en cuestión la afirmación relativa al acotado ámbito temporal y espacial en el que se inscriben estas acciones. Al respecto resulta interesante observar que, en prácticamente la totalidad de los casos, los linchamientos terminan con la intervención de la policía, cuestión que en definitiva significa que estas acciones, en tanto violencia sobre el cuerpo del ofensor, terminan cuando este se inscribe en los procedimientos de la burocracia asociada al Estado moderno.

En algunas ocasiones, a la vez que se ejerce violencia sobre el cuerpo del linchado, se apela a la intervención de la policía. "La mujer dio alerta de inmediato a Carabineros y mientras esperaban su llegada, fueron a enfrentar al delincuente... Carabineros se hizo presente en el sitio, llevándolo detenido tras recibir una golpiza de los pobladores" (5). Y en un par de casos estas acciones se desarrollan afuera de edificios institucionales vinculados a los operadores del sistema de administración de justicia. "Cuando el sujeto fue llevado a la comisaría para realizar el control de detención, los tocopillanos comenzaron a atacar el recinto" $(6, b)$. Ambas circunstancias permiten conectar el espacio local con las instituciones propias del Estado de Derecho y por tanto nos remiten a espacios extendidos.

El que la intervención de la policía signifique la clausura del linchamiento nos remite a la idea de una relación diacrónica entre el acotado tiempo asociado al desarrollo de los linchamientos y los tiempos más extendidos propios de los procedimientos formales del poder central del Estado y su derecho. Por su parte, la apelación a la intervención de la policía y las acciones que se desarrollan afuera de edificios institucionales nos remiten a la posibilidad de una relación sincrónica entre el espacio local y el poder central del Estado y su derecho en el desarrollo de los linchamientos.

\subsection{Autonomía e interdependencia}

Los linchamientos podrían dar cuenta de la desafección del derecho centralizado del Estado, posibilitada por los grados de autonomía propios de ciertos niveles de desarrollo y diferenciación de las sociedades (Elias, 2009).

A su vez, esta desafección podría incidir en una disminución de la interdependencia de los excluidos del Estado de Derecho respecto del resto de la sociedad en lo que dice relación con el ámbito jurídico. Los marginados del Estado de Derecho en su experiencia cotidiana, al desarrollar prácticas que implican autonomía en la resolución de conflictos, tenderían a autosustraerse de la interacción con el poder central en este ámbito. 
Por su parte el poder central, debido a los niveles de complejidad propios de la sociedad actual, depende para la conservación y administración de ese poder del entramado de personas que están subordinadas a él, de ahí que no puedan libremente anular o reprimir acciones que representan el sentir de un conjunto de sujetos (Elias, 2009).

\subsubsection{Intervención de la policía en tanto agentes operadores del derecho}

Anteriormente señalamos que, salvo en el caso en que el resultado del linchamiento fue la muerte del linchado, estas acciones siempre tienen su punto final cuando interviene la policía. La intervención de la policía sobre estas acciones apunta a la inscripción del sujeto que es objeto de la violencia desplegada en la institucionalidad del Estado y su sometimiento a sus procedimientos. "La policía lo rescató y lo tomó detenido" (13). Ello sin perjuicio del resultado específico de tales procedimientos ${ }^{2}$.

La policía interviene entonces en tanto agente operador del derecho, pero se trata de una operación del derecho anómala, ya que no se inscribe a la vez en los procedimientos propios de la institucionalidad represiva del Estado moderno a los linchadores, existiendo mérito para ello. El único caso en el que la intervención de la policía se dirige contra los linchadores en razón de la violencia que se ejerce sobre el cuerpo del linchado es en el caso cuyo resultado es la muerte de este último. Pareciera que la muerte del linchado marca una diferencia en cuanto a la forma de operación del derecho; en estas circunstancias la práctica del aparato jurídico se hace eco de su discurso y aspira a la represión de quienes ejercieron violencia al margen de la institucionalidad del Estado de Derecho.

\subsubsection{Interacción entre los linchadores y los operadores del derecho}

En todos los casos, salvo el que tuvo como resultado la muerte del linchado, la interacción entre los linchadores y los operadores del derecho está marcada por el traspaso del cuerpo del sujeto sobre el que se pretende infringir daño desde la esfera de acción de los primeros al dominio de estos últimos, sin que se observen datos que revelen que con posterioridad a ello los operadores del derecho se orienten a la represión de los linchadores.

Algunas veces el traslado del sujeto sobre el que se despliega la violencia, desde la esfera de acción de los linchadores a la esfera de acción de la policía, pareciera darse por medio de una entrega pacífica: "Carabineros se hizo presente en el sitio, Ilevándolo detenido tras recibir una golpiza de los pobladores" (5). También existen casos en que el sujeto que es objeto del linchamiento ya está en manos de la policía o tribunales y durante la acción estos actúan reteniéndolo en su poder: "El acusado se encontraba en el interior del recinto policial... Hasta donde llegó la turba" (6, a).

2 En un número reducido de casos se relata que la acción de la policía se dirige también contra los sujetos que participan del linchamiento, sin embargo en estos casos la violencia desborda el objeto propio del linchamiento, esto es el cuerpo del linchado, y se muestra más difusa en cuanto a su propósito. 
Por último, hay casos en los que del relato se infiere que la policía sustrae al sujeto objeto de la acción del linchamiento contra la voluntad de quienes participan de este: "Solo la llegada de la policía evitó un linchamiento" (4); "La llegada de Carabineros salvó al aporreado delincuente" (11); "Todo terminó con la intervención de Carabineros" (13). También resulta pertinente tener en cuenta que en algunas ocasiones la intervención del derecho, representado por la policía, parece ser invocada por los propios linchadores: "Alertaron a los uniformados e intentaron linchar al hombre" (9, c).

Las circunstancias descritas permiten cuestionar la lectura de los linchamientos como simples manifestaciones atávicas de formas de ser del derecho penal porque conectan el desarrollo de estas acciones, que inicialmente parecieran autárquicas frente al poder del Estado, con los operadores del sistema jurídico centralizado de este.

\subsubsection{Momento en el que interviene el derecho}

El que la intervención de la policía sea el hito que marca el fin del linchamiento -en tanto esta intervención supone, salvo en el caso en el que el resultado es la muerte del linchado, que el sujeto que es objeto de esta acción es sacado de la esfera de acción de los linchadores y se lo procesa institucionalmente- implica que estas acciones, que inicialmente emergen como formas autárquicas de resolver conflictos, provocan en definitiva la apertura de esa misma autarquía y la intervención del poder central y más específicamente del derecho, representado por su aparato coactivo burocrático especializado, elemento que, según Weber, caracteriza al derecho propio de los Estados modernos (Fariñas, 1991).

El que los linchamientos se clausuren a propósito de la intervención de la policía implica una conexión del espacio local, en el que inicialmente germinan estas acciones, con un espacio mayor, que lo excede, en el que al parecer se inserta. Esto podría estar dando cuenta de una especie de cadena de control social en la que el primer eslabón, el linchamiento, presenta formas de interacción funcionales a sociedades con bajos niveles de diferenciación e interdependencia, pero paradójicamente estas acciones gatillarían otras formas de interacción radicalmente diferentes, que dan cuenta a su vez de otro tipo de estructuras sociales.

Sin embargo existen un par de casos en los que el derecho, mediante sus operadores, interviene antes del linchamiento: "A la salida del tribunal decenas de familiares y vecinos... lo esperaban para hacer justicia con sus propias manos" $(8, b)$; "Cuando el sujeto fue llevado a la comisaría para realizar el control de detención, los tocopillanos comenzaron a atacar el recinto" $(6, b)$. Estos casos cuestionan la idea que los linchamientos operan en una especie de cadena de control social con el derecho, motivando su intervención.

En ambos casos los hechos que originan el linchamiento son los mismos y corresponden a acciones que lesionan gravemente la vida y la libertad sexual de menores de edad: se trata de homicidios con violación. A su vez, estos son los únicos dos casos de la muestra en los que la ofensa que genera el linchamiento corresponde a esta combinación de acciones. 
Se podría sospechar entonces que, cuando la ofensa radica en lesiones graves a la vida y a la libertad sexual, el linchamiento no opera como el primer eslabón del control social, sino que se desarrolla en paralelo a la activación del derecho del Estado y como una especie de seguimiento del actuar de este.

Lo descrito podría llevarnos a pensar en la coexistencia sincrónica, en distintos niveles, de formas de control social divergentes. La articulación entre los linchamientos y el derecho no podría estar representada únicamente por la idea de una cadena de control social. Por el contrario, dicha articulación podría estar dando cuenta del afloramiento esporádico de espacios relativamente autárquicos respectos del poder central, intersticios que sin embargo no reivindican su autonomía respecto de ese poder, sino que por el contrario cuentan con él.

Estos espacios nunca aparecen totalmente clausurados, ni se constituyen como una constante, sino que emergen o se constituyen a partir de ciertos hitos para los cuales sus formas de operación resultan funcionales, pero se trata de una funcionalidad restringida a esos mismos espacios.

El que el único caso en el que el resultado fue la muerte del linchado sea a su vez el único en el que la intervención de la policía sucede con posterioridad al fin del linchamiento, reafirma la posibilidad de una estrecha conexión entre la intervención de la policía y la manera en que estas acciones se desarrollan.

El derecho propio de los Estados modernos se encuentra aparentemente incorporado en el despliegue de la secuencia de actos que incluyen los linchamientos. Siguiendo a Rodríguez y Mora (2005), los linchamientos tendrían, además de su evidente carácter reactivo, un carácter restitutivo, debido a que se orientan hacia la restitución de la autoridad, aunque sea por medios violentos.

\subsection{Contenido político de los linchamientos}

Los linchamientos tienen un contenido político, por cuanto la violencia colectiva desplegada en ellos constituye una forma de contienda política. "Contienda porque los participantes reivindican algo que afecta a sus respectivos intereses y política porque siempre está en juego la relación de los participantes con el gobierno" (Tilly, 2007: 25).

Estas acciones cuestionan la autoridad a nivel microsocial (Rodríguez y Mora, 2005), estrato relevante en la medida en que la mayoría de los sujetos construye allí sus juicios de legitimidad, en tanto es en este nivel sobre el que se posee o espera poseer alguna capacidad de decisión (Vilas, 2001).

\subsubsection{Conductas que originan los linchamientos}

De acuerdo con la información revisada, los hechos que originan los linchamientos, salvo en un caso, son acciones que se encuentran tipificadas como conductas desviadas en el derecho del Estado. Se trata de incendios, lesiones (por atropello), robos, abusos sexuales, violaciones y homicidios. 
Esto constituye un indicio respecto de que los participantes de los linchamientos en ningún caso poseen un conjunto de creencias y valoraciones de lo bueno y lo malo divergente del marco que se expresa mediante las normas sustantivas del derecho positivo.

\subsubsection{El caso desviado}

El único caso en el que la conducta que se pretende sancionar por medio del linchamiento no es significada también como una conducta reprochable por el derecho estatal, corresponde a un caso en el que en medio de una marcha se acusa a dos sujetos de ser policías encubiertos: "Manifestantes [marcha del 21 de mayo] habrían tratado de linchar a dos sujetos al descubrir que estos eran en realidad detectives de la Policía de Investigaciones que se encontraban trabajando de civil" (12).

Si observamos la ofensa que provoca el linchamiento en este caso, vemos que se refiere a los procedimientos de uno de los cuerpos operadores del derecho, la policía. Ello pone de manifiesto que lo problemático de estas acciones en relación con el derecho, su contenido político, reside en los procedimientos e instituciones asociadas a la administración de dicha normatividad. El conflicto del que dan cuenta los linchamientos, en un nivel abstracto, se situaría más bien en el campo de la operación del sistema jurídico, el cómo se administra el derecho.

\subsubsection{Indicios de apelación y/o desafío al derecho}

En algunos casos, a la vez que se desarrollan varios actos violentos sobre un sujeto, se apela a la presencia de la policía. Esto implica que no existe una relación de exclusión entre el desarrollo de la violencia y la invocación de la presencia de la autoridad pública.

También se advierten circunstancias que revelan que los linchamientos aparecen enfrentando directamente a la institucionalidad asociada al derecho. La violencia se despliega sobre los agentes y las instituciones que en definitiva hacen funcionar ese derecho, el aparato burocrático especializado en la administración de la coacción física que según Weber permite identificar al derecho propio de los Estados modernos: "Cerca de las 7 de la mañana Carabineros trataba de disuadir y dispersar a la muchedumbre que seguía destruyendo el auto, encendiendo barricadas y causando destrozos" $(1, a)$; "Los manifestantes incluso apedrearon el vehículo policial que lo trasladaba a la $39^{\circ}$ comisaría" $(17$, b).

Las acciones que representan un desafío al derecho podrían dar cuenta de un contenido político que denote algún tipo de ideal de derecho distinto del derecho moderno, pero estos reclamos están representados por acciones inacabadas, truncadas por el despliegue de la fuerza pública, acciones que por lo tanto no alcanzan a dar cuenta de alguna propuesta que pueda identificarse como aspiración, sino que solo alcanzan el momento de la disputa y se trata además de una disputa incompleta por cuanto estos actos siempre desembocan de una u otra manera en la intervención del derecho estatal.

El único caso en el que se puede vislumbrar el linchamiento como una operación cerrada, en tanto acción en la que no interviene el derecho del Estado ni se reclama su falta 
o forma de intervención, es el caso en el que el resultado del linchamiento es la muerte del linchado. En lo que respecta a este caso, de la información contenida en las notas de prensa examinadas no se aprecia que quienes participaron de esta acción, ni quienes dan testimonio de ella, la reivindiquen.

En definitiva no existe información en los archivos examinados que permita advertir, con base en los linchamientos, la aspiración a un derecho radicalmente distinto del que conocemos.

La adscripción al discurso del derecho moderno, a pesar del desarrollo de prácticas que pueden ser reveladoras respecto del incumplimiento de dicho discurso, puede comprenderse a partir de la utilización de procedimientos de moralización de las clases pobres, los que han tenido una importancia capital en la adquisición de un legalismo de base, indispensable desde el momento en que el derecho estatal "contiene las reglas elementales de la propiedad y del ahorro; enseñanza de la docilidad en el trabajo, de la estabilidad del alojamiento y de la familia" (Foucault, 2002: 265).

\subsection{Los linchamientos y la administración de la violencia}

\subsubsection{Los linchamientos: ¿una conducta desviada?}

El único episodio en que es claramente observable la valoración del linchamiento como una acción reprochable por el derecho corresponde al episodio que tuvo como resultado la muerte del linchado: "Efectivos de la Policía de Investigaciones arrestaron a... tras ser acusado de ser una de las personas que ajustició a... Los cómplices también acudieron a prestar declaraciones a la Policía de Investigaciones" (3, d). Ello no obstante que en todos los casos se advierte al menos la intención de infringir daño sobre el cuerpo de un sujeto.

Esto último permite sugerir la identificación de los linchados como seres humanos sin el manto protector del consenso sobre su humanidad: aquellos que pueden ser sacrificados impunemente (Agamben, 1998). El castigo dado por los linchadores se centra en el suplicio como técnica de sufrimiento, desapareciendo el linchado como un ciudadano titular de derechos.

Sin embargo, la actuación de la institucionalidad del derecho sobre los linchadores en el caso en el que la acción tuvo como resultado la muerte del linchado nos podría indicar que la posibilidad de sacrificar impunemente a un ser humano tiene una frontera que dice relación con la magnitud de dicho daño: la muerte como resultado de esa violencia aparece como intolerable.

\subsubsection{Dosificación de la violencia}

La constatación de la existencia de solo un caso con resultado de muerte y de la actuación represiva de los agentes e instituciones del Estado sobre los linchadores, constituyen circunstancias que permiten sospechar que el linchamiento resulta funcional en la medida 
que existe una suerte de economía de la violencia implicada en dicha acción. Resulta entonces conveniente pesquisar información acerca de la magnitud de los daños infringidos sobre el cuerpo del linchado.

Solo un par de relatos dan cuenta del alcance de las lesiones producidas. En estos casos el contenido de los archivos permite advertir que los maltratos no derivaron en heridas especialmente graves, que pusieran en peligro la salud o la vida del sujeto. Otros relatos indican que el sujeto sobre el que se ejerce la violencia es detenido y trasladado a dependencias policiales o a constatar lesiones, acciones que suponen que los golpes que recibió y las heridas sufridas fueron de una magnitud menor en tanto estas no hicieron necesaria la asistencia médica al sujeto.

Esta observación resulta coherente con lo observado en algunos casos en cuanto a que los actos que implican proferir daño físico al cuerpo del sujeto linchado cesaron antes de la llegada de la policía, aun cuando quienes participan del linchamiento retienen al sujeto hasta su llegada.

La limitada magnitud de los daños autoriza la sospecha sobre un cierto orden, dirección y control de la violencia. El objetivo de obtener un cierto beneficio a raíz del ejercicio de violencia sobre el cuerpo del linchado, esto es el utilizar la violencia como un recurso, podría explicar esta suerte de dosificación de su uso.

\section{CONCLUSIONES}

El examen de los linchamientos a la luz del derecho, entendiendo este como un fenómeno que se constituye como "una expresión de las relaciones sociales de fuerza" (Elias, 2009: 372), permite destrabar la mirada sobre estas acciones como episodios en los que el derecho simplemente desaparece. Por el contrario, revela que estas acciones se relacionan con el derecho, pero lo hacen de manera paradójica.

Afirmamos que dicho vínculo es paradójico porque de la descripción de los distintos actos implicados en estas acciones se advierte que ellos están en contradicción con el canon del derecho moderno, lo que sugiere un fundamento para la significación de estas acciones como espacios vacíos de derecho. Sin embargo estas acciones, a la vez que aparecen como la antítesis de las formas de interacción legitimadas por el derecho moderno, apelan, involucran y/o comprometen la intervención de este. En efecto, dicha intervención efectivamente ocurre en la casi totalidad de los casos, pero no sigue la línea de la contradicción en tanto no se orienta a la represión de los linchadores. Incluso en la mayoría de los casos se observa que confluye con el objetivo de estos, por cuanto la intervención de la policía apunta al control del sujeto sobre el que los linchadores pretenden ejercer violencia.

Por otra parte, el carácter público con que se despliega la violencia asociada a los linchamientos, la forma en que habitualmente estas acciones se conectan con los operadores del derecho, la dosificación de la violencia implicada en ellas, la regularidad en su desarrollo y la aparente falta de represión por parte de los operadores del derecho 
contra los linchadores, permiten sugerir la posibilidad de estar asistiendo a la emergencia de un proceso de normalización de estas acciones, aun cuando es necesario advertir que la información examinada solo permite visibilizar una especie de normalización situada, en tanto no contiene evidencia que permita afirmar la validación de estas acciones más allá del momento y el espacio en el que acontecen.

Sin embargo, y a pesar de que la descripción de los linchamientos permite revelar la existencia de vínculos de estas acciones con la institucionalidad asociada al derecho moderno y en cierta medida la recepción de su discurso, o al menos la no supresión total de este, los comportamientos, tanto de quienes participan de los linchamientos como de los operadores del derecho, no coinciden con lo que se esperaría como consecuencia de la presencia del derecho moderno en el desarrollo de estas acciones. Los linchamientos revelan entonces cierto desajuste del paradigma del derecho moderno en tanto un paradigma implica la suposición de que solo se presentarán cierto tipo de circunstancias (Kuhn, 2004).

Si el discurso del derecho moderno es compartido por los linchadores y operadores del derecho, estas acciones deberían tener un carácter más bien oculto, y en la medida en que la policía se percatase de ellas debiera reprimir a quienes están ejerciendo violencia sobre el cuerpo del linchado, pero lo que sucede es todo lo contrario. Esta realidad nos remite a la noción de crisis en tanto situación de disconformidad y de contradicciones entre el ordenamiento regulador y el procedimiento que aquella supuestamente condiciona (Wolkmer, 2006).

La posibilidad de una crisis del derecho moderno se inscribe en el contexto de la crisis de los Estados. A fines del siglo XX hasta los Estados más poderosos dependen de una economía mundial sobre la que no pueden ejercer control alguno (Hobsbawn, 1998), realidad que redunda en la debilitación de esta forma de organización política, circunstancia que se hace manifiesta a la hora de solucionar los conflictos en su interior (Villoro, 1998).

Ahora bien, la idea de una posible crisis del derecho debe ser morigerada a propósito de que la idea de una cierta legitimación de los linchamientos se encuentra asociada a la dosificación de la violencia, que se administra y se conecta en algún punto con la intervención de la policía en tanto agentes del derecho. La policía sustrae al sujeto sobre el que se intenciona la violencia y lo inscribe en los procedimientos e institucionalidad propios del aparato coactivo-burocrático especializado propio del derecho del Estado. De lo contrario, si la violencia no se administra sino que se desata, si los linchamientos no se conectan en algún punto de su desarrollo con los operadores del derecho, entonces provocan una reacción del aparato jurídico que se orienta decididamente a su represión.

Pareciera que los linchamientos se constituyen como formas de interacción legitimadas en el espacio y momento en el que transcurren, en la medida en que se presenten como intersticios moderados en una institucionalidad jurídica que los antecede y los precede, con la que se conecta.

Sin embargo, y a pesar de la idea de una cierta regulación de la graduación de la violencia sobre el cuerpo del linchado, igualmente es factible asociar estas acciones a la noción del 
ser humano como sacrificable (Agamben, 1998), en la medida en que los linchamientos, a pesar de significar la intención y/o el efectivo despliegue de violencia sobre un cuerpo humano, no son descritos en los relatos contenidos en los archivos de prensa como acciones reprochadas social ni institucionalmente, salvo el caso en el que el resultado de la acción es la muerte del linchado. El castigo vuelve a ser el arte de infringir sensaciones de dolor sobre un cuerpo y deja de significar una economía de los derechos suspendidos de un sujeto jurídico (Foucault, 2002).

No obstante las limitaciones del presente trabajo, es posible adelantar que los elementos que revelan la existencia de la tensión entre los linchamientos y el derecho no permiten vislumbrar la existencia de un ideal de derecho completamente distinto asociado a estas acciones. Parece más bien que la tensión se centra en la operación del derecho.

Sin embargo, lo relativo a la forma en que el derecho opera no es un asunto menor, porque los procedimientos asociados a la administración de los conflictos que se consignan como relevantes en una sociedad, y que consiguientemente adoptan el carácter de conflictos jurídicos, constituyen una parte fundamental de la configuración sustantiva de un sistema de derecho determinado.

En este sentido es preciso recordar la centralidad que tuvo en la configuración del derecho en su conjunto el cambio del modelo bélico de resolución de conflictos, propio del derecho germánico medieval, al método indagatorio, identificado con el derecho moderno. Este cambio situado a nivel concreto en el plano procedimental da cuenta de transformaciones paradigmáticas del derecho y, en términos generales, se constituye como una manifestación de los procesos de transformación de las estructuras sociales (Foucault, 2005).

En el caso de los linchamientos, el que en la información analizada solamente existan evidencias relativas al carácter situado de un posible emergente proceso de normalización de estas acciones no permite aventurar la extensión del alcance de la tensión relativa a la operación del derecho.

Además, los puntos de convergencia de los linchamientos con el derecho del Estado moderno y la funcionalidad de aquellos en relación a este, consistente en que los primeros aparecen gatillando la intervención del segundo o presionando sobre las decisiones que toman sus operadores, permiten sospechar que estas acciones comparten el discurso de la igualdad jurídica, central en este derecho, y en esa medida no cuestionan su desencuentro con la desigualdad material y podrían tender a reproducir y/o a naturalizar ese desencuentro y esa desigualdad material.

Podría ser justamente el moderno derecho estatal el que, a propósito de las expectativas que genera su discurso compartido, pero incumplido, en lo relativo a la igualdad, engendraría en alguna medida el despliegue de violencia física asociado a los linchamientos como desafío, sucedáneo y al mismo tiempo reclamo respecto de esas expectativas incumplidas, y a la vez sería este mismo derecho, a través de sus operadores, el que controla esta violencia en cuanto a su clausura. Los linchamientos se revelan desde esta perspectiva como acciones solo aparentemente insurgentes. 
Los linchamientos representarían entonces estados de excepción del derecho moderno, localizados y temporales. Se advierte así que estas acciones se inscriben como un paréntesis anómalo a una institucionalidad jurídica que lo antecede y lo precede y a la que sin embargo resultan funcionales.

La ocurrencia reiterada de linchamientos, en tanto formas de interacción divergentes del derecho moderno, coexistiendo y relacionándose con este modelo jurídico sin que este tienda a su represión, los hacen aparecer como una exención regular, lo que sugiere una especie de economía de ilegalidad, tolerada por el derecho como condición del funcionamiento de una sociedad tensionada. Se trataría de una organización de la producción, intercambio y distribución de ilegalidad, con el objeto de satisfacer intereses concretos mediante los recursos disponibles. Es decir, habría una cierta administración de los linchamientos en tanto ilegalismos, tanto por parte de quienes ejercen la violencia implicada en ellos como por parte de los operadores del derecho del Estado, administración que apunta a sacar provecho de estos (Foucault, 2002).

La observación de dicha articulación quita sustento a la idea de una crisis del derecho posible de rastrear por medio del examen de los linchamientos. No obstante ello, lo paradójico de dicha articulación permite conjeturar la posibilidad de una crisis latente.

\section{BIBLIOGRAFÍA}

Agamben, G. (1998): Homo Sacer. El poder soberano y la nuda vida, Pre-Textos, Valencia.

Auyero, J. y M. Berti (2013): La violencia en los márgenes. Una maestra y un sociólogo en el conurbano bonaerense, Katz, Buenos Aires.

Benjamin, W. (1998): Para una crítica de la violencia y otros ensayos, Taurus, Madrid.

Berger, P. y T. Luckmann (1968): La construcción social de la realidad, Amorrortu, Buenos Aires.

Carrión, F. (2008): “¿Quién es Fuenteovejuna? Todos a una, Señor”, Boletín Ciudad Segura, 22, disponible en works.bepress.com/fernando_carrion/236 (recuperado el 05/09/2013).

Durkheim, E. (1995): La división del trabajo social, Ediciones Akal, Madrid.

Elias, N. (2009): El proceso de la civilización: investigaciones sociogenéticas y psicogenéticas, Fondo de Cultura Económica, México D.F.

Fariñas, M. (1991): La sociología del derecho de Max Weber, Civitas, Madrid.

Foucault, M. (2002): Vigilar y castigar: nacimiento de la prisión, Siglo XXI, Buenos Aires.

(2005): La verdad y las formas jurídicas, Gedisa, Barcelona.

Fuentes, A. (2005): "El Estado y la furia", El Cotidiano, 131, pp. 7-19, disponible en www.redalyc.org/ pdf/325/32513102.pdf (recuperado el 06/09/2013).

(2006): "Subalternidad y violencia colectiva en México y Guatemala", Fermentum. Revista Venezolana de Sociología y Antropología, 16 (46), pp. 415-428, disponible en www.redalyc. org/pdf/705/70504608.pdf (recuperado el 10/07/2013).

González, L., J. Ladeuix y G. Ferreyra (2011): “Acciones colectivas de violencia punitiva en la Argentina reciente", Bajo el Volcán, 10, pp. 165-193. 
Hobsbawn, E. (1998): Naciones y nacionalismo desde 1780, Crítica, Barcelona.

Krippendorff, K. (1990): Metodología de Análisis de Contenido: teoría y práctica, Paidós, Barcelona.

Kuhn, T. (2004): La estructura de las revoluciones científicas, Fondo de Cultura Económica, Buenos Aires.

López, F. (2002): "El análisis de contenido como método de investigación", Revista de Educación, 4, pp. 167-179, disponible en www.uhu.es/publicaciones/ojs/index.php/xxi/article/view/610/932 (recuperado el 05/11/2014).

Pérez, C. (1996): La construcción social del derecho, Universidad de Sevilla, Sevilla.

Rodríguez, C. (coord.) (2011): El derecho en América Latina. Un mapa para el pensamiento jurídico del siglo XXI, Siglo XXI, Buenos Aires.

Rodríguez, R. y J. Mora (2005): "Los linchamientos en México: entre el Estado de Derecho y los usos y costumbres", El Cotidiano, 129, pp. 56-67.

(2008): "Derechos humanos y linchamientos en México", El Cotidiano, 150, pp. 63-72, disponible en redalyc.uaemex.mx/pdf/325/32515010.pdf (recuperado el 05/09/2013).

Santos, B. de S. (2009): Sociología jurídica crítica. Para un nuevo sentido común en el derecho, Trotta, Madrid.

Sinhoreto, J. (1988): Linchamentos e resoluçao de litigios: estudos de caso de periferias de SP, Ponencia presentada en el XXII Encontro Anual da Associaçao Nacional de Pos Graduaçao e Pesquisa em Ciencias Sociales (ANPOCS), 27-31 de octubre, Coxambú, Brasil, disponible en http://portal. anpocs.org/portal/index.php?option=com_docman\&task=doc_view\&gid=5201\&ltemid=359 (recuperado el 05/04/2013).

Tilly, C. (2007): Violencia colectiva, Hacer, Barcelona.

Vilas, C. (2001): “(In) Justicia por mano propia: Linchamientos en el México contemporáneo”, Revista Mexicana de Sociología, 63 (1), pp. 131-160, disponible en www.jstor.org/discover/3541204 ?sid=21104996463441\&uid=4\&uid=2 (recuperado el 01/04/2013).

(2006): "Linchamientos y lucha política en los Andes", El Cotidiano, 21 (140), pp. 115-129, disponible en www.redalyc.org/pdf/325/32514011.pdf (recuperado el 15/04/2013).

Villoro, L. (1998): “Del Estado homogéneo al Estado Plural”, en L. Villoro: Estado Plural, pluralidad de culturas, UNAM/Paidós, México D.F., pp. 13-62.

Wolkmer, A. (2006): Pluralismo jurídico. Fundamentos de una nueva cultura del derecho, MAD, Sevilla.

Recibido: 02-07-2015

Aceptado: 23-07-2015 
ANEXO: UNIDADES DE MUESTREO

\begin{tabular}{|c|c|c|c|c|}
\hline $\mathrm{N}^{\circ}$ & FECHA & LUGAR & ACUSACIÓN & FUENTE $^{3}$ \\
\hline 1 & 01.01 & $\begin{array}{l}\text { Región: Valparaíso } \\
\text { Comuna: Valparaíso }\end{array}$ & Atropello & $\begin{array}{l}\text { (a) LN } 02.01 \\
\text { (b) LN } 02.01\end{array}$ \\
\hline 2 & Sin información & Región: Arica & Robo & EM/SC 27.01 \\
\hline 3 & 01.02 & $\begin{array}{l}\text { Región: Metropolitana } \\
\text { Comuna: La Granja }\end{array}$ & Robo y abuso sexual & $\begin{array}{l}\text { (a) LC } 02.02 \\
\text { (b) EM/SC } 02.02 \\
\text { (c) LN } 02.02 \\
\text { (d) LN } 02.02\end{array}$ \\
\hline 4 & Sin información & $\begin{array}{l}\text { Región: Metropolitana } \\
\text { Comuna: Providencia }\end{array}$ & Robo & LN 15.02 \\
\hline 5 & 24.02 & $\begin{array}{l}\text { Región: Antofagasta } \\
\text { Comuna: Calama }\end{array}$ & Robo & EM/SC 25.02 \\
\hline 6 & 26.02 & $\begin{array}{l}\text { Región: Antofagasta } \\
\text { Comuna: Tocopilla }\end{array}$ & $\begin{array}{l}\text { Violación y } \\
\text { homicidio de menor } \\
\text { de edad }\end{array}$ & $\begin{array}{l}\text { (a) LC } 27.02 \\
\text { (b) EM/SC } 27.02 \\
\text { (c) EM } 01.03\end{array}$ \\
\hline 7 & Sin información & $\begin{array}{l}\text { Región: Antofagasta } \\
\text { Comuna: Calama }\end{array}$ & Robo & EM/SC 03.03 \\
\hline 8 & 10.03 & $\begin{array}{l}\text { Región: Biobío } \\
\text { Comuna: San Pedro de la Paz }\end{array}$ & $\begin{array}{l}\text { Violación y } \\
\text { homicidio de menor } \\
\text { de edad }\end{array}$ & $\begin{array}{l}\text { (a) LC } 11.03 \\
\text { (b) LC } 12.03\end{array}$ \\
\hline 9 & 16 o 17.03 & $\begin{array}{l}\text { Región: Metropolitana } \\
\text { Comuna: Quilicura }\end{array}$ & $\begin{array}{l}\text { Abuso sexual de } \\
\text { menores de edad }\end{array}$ & $\begin{array}{l}\text { (a) LC } 19.03 \\
\text { (b) LC } 20.03 \\
\text { (c) EM/SC } 19.03 \\
\text { (d) LN } 19.03\end{array}$ \\
\hline 10 & 12.05 & $\begin{array}{l}\text { Región: Antofagasta } \\
\text { Comuna: Antofagasta }\end{array}$ & Robo & EM 12.05 \\
\hline
\end{tabular}

3 Abreviaturas: 


\begin{tabular}{|c|c|c|c|c|}
\hline$N^{\circ}$ & FECHA & LUGAR & ACUSACIÓN & FUENTE $^{3}$ \\
\hline 11 & Sin información & $\begin{array}{l}\text { Región: Biobío } \\
\text { Comuna: Concepción }\end{array}$ & Robo & LN 15.05 \\
\hline 12 & 21.05 & $\begin{array}{l}\text { Región: Valparaíso } \\
\text { Comuna: Valparaíso }\end{array}$ & $\begin{array}{l}\text { Policías encubiertos } \\
\text { en marcha }\end{array}$ & EM 21.05 \\
\hline 13 & 12.07 & $\begin{array}{l}\text { Región: La Araucanía } \\
\text { Comuna: Temuco }\end{array}$ & Abuso sexual & LN 15.02 \\
\hline 14 & 05.08 & $\begin{array}{l}\text { Región: Metropolitana } \\
\text { Comuna: Huechuraba }\end{array}$ & Incendio & EM 06.08 \\
\hline 15 & 17.08 & $\begin{array}{l}\text { Región: Atacama } \\
\text { Comuna: Copiapó }\end{array}$ & Robo & $\begin{array}{l}\text { (a) EM/SC } 17.08 \\
\text { (b) EM/SC } 21.08\end{array}$ \\
\hline 16 & Sin información & $\begin{array}{l}\text { Región: Valparaíso } \\
\text { Comuna: Los Andes }\end{array}$ & Abusos sexuales & LN 23.08 \\
\hline 17 & Sin información & $\begin{array}{l}\text { Región: Metropolitana } \\
\text { Comuna: El Bosque }\end{array}$ & $\begin{array}{l}\text { Violación de una } \\
\text { menor de edad }\end{array}$ & $\begin{array}{l}\text { (a) LC } 21.12 \\
\text { (b) EM/SC } 21.12 \\
\text { (c) LN } 21.12\end{array}$ \\
\hline
\end{tabular}

